\title{
A STUDY ON THE PATTERN OF BLOOD PRESSURE AND ITS CO-RELATES AMONG THE PATIENTS ATTENDING THE GERIATRIC CLINIC OF GAUHATI MEDICAL COLLEGE AND HOSPITAL, GUWAHATI
}

\author{
Shashanka Shekhar Chakraborty1, Jutika Ojah² \\ ${ }^{1}$ Assistant Professor, Department of Community Medicine, Gauhati Medical College, Guwahati. \\ 2 Professor and HOD, Department of Community Medicine, Gauhati Medical College, Guwahati.
}

ABSTRACT
BACKGROUND
All over the world, the geriatric population is growing continuously and it is projected that by the year 2025 majority of the
elderly population will be residing in the developing countries, especially India. Cardiovascular Diseases (CVD) are the major cause
of death among the elderly population in which High Blood Pressure plays an important role.

AIM

To study the pattern of Blood Pressure and its co-relates among the elderly patients attending the Geriatric Clinic.

Setting: Hospital-based Cross-sectional study.

\section{MATERIALS AND METHODS}

All the patients those who attended the Geriatric Clinic during the study period were taken. Predesigned, pretested interview schedule was used to collect the information from the patients and also to note down the physical examination findings.

\section{STATISTICAL ANALYSIS}

Chi-squared test, t-test were done. Odds ratio with 95\% CI was calculated wherever applicable.

\section{RESULTS}

Among all the patients, $16.04 \%$ were found to be hypertensive. Prevalence is found to be highest among those in the age group of 75 years or more. Hypertension was found to be $17.81 \%$ among the male patients compared to $12.89 \%$ among the females. Hypertension was found to be significantly associated with increasing age, family type and socio-economic status ( $\mathrm{p}<0.05$ ). Hypertension was also found to be significantly associated with co-relates like age, non-vegetarian diet, history of alcohol intake, history of smoking, history of use of chewable tobacco ( $\mathrm{p}=0.0031, \mathrm{p}=0.0017, \mathrm{p}<0.0001, \mathrm{p}=0.0121)$. There was significant difference in mean BP between the normotensive and hypertensive patients across all the age groups in both males and females. There was significant association between BMI and hypertension in both males and females.

\section{CONCLUSION}

The blood pressure pattern among the geriatric population tends to increase with increasing age and other behavioural risk factors.

\section{KEYWORDS}

Hypertension, Geriatric, BMI, Smoking, Blood Pressure.

HOW TO CITE THIS ARTICLE: Chakraborty SS, Ojah J. A study on the pattern of blood pressure and its co-relates among the patients attending the geriatric clinic of Gauhati Medical College and Hospital, Guwahati. J. Evolution Med. Dent. Sci. 2016;5(47):3011-3016, DOI: $10.14260 /$ jemds/2016/701

\section{INTRODUCTION}

Elderly or old age consists of ages nearing or surpassing the average life span of human beings. The boundary of old age cannot be defined exactly, because it does not have the same meaning in all societies. People can be considered old, because of certain changes in their activities or social roles. Also old people have limited regenerative abilities and are more prone to disease, syndromes and sickness as compared to other adults. India is in demographic transition phase and is expected to be next greying country very soon in the world.

Financial or Other, Competing Interest: None.

Submission 26-04-2016, Peer Review 20-05-2016,

Acceptance 26-05-2016, Published 13-06-2016.

Corresponding Author:

Dr. Shashanka Shekhar Chakraborty,

Department of Community Medicine,

Gauhati Medical College (5 $5^{\text {th }}$ Floor),

Narakasur Hilltop,

P.O. Indrapur,

Bhangagarh,

Guwahati-781032.

E-mail:drshashank79@gmail.com

DOI: $10.14260 /$ jemds $/ 2016 / 701$
As per United Nations Population Division (2011), the share of India's population aged 60 and older is projected to climb from $8 \%$ in 2010 to $19 \% 2050$ within a span of four decades.(1) With the increasing trend in the life expectancy, there have been increased morbidities among the geriatric age group. Chronic diseases (NCDs) like Cardiovascular Diseases, Hypertension, Diabetes, Cancer, Joint Pain are the major morbidities found among the elderly.(2) In India, NCDs were found to be responsible for $53 \%$ of total deaths and $44 \%$ of Disability Adjusted Life Years (DALY) lost among the elderly.(3)

Of all the non-communicable diseases, the degenerative diseases of heart and blood vessels are of utmost importance.(4)

Hypertension, a key NCD risk factor appears to be increasing in prevalence, possibly associated with development, urbanization and lifestyle changes.(5) Hypertension is a modifiable risk factor for Cardiovascular Disease (CVD). Data from the Framingham Heart Study showed increasing cardiovascular morbidity with increasing systolic or diastolic pressure in those aged 65 and over.(6) Hypertension prevalence increases with age and is a readily treatable risk factor for the most common causes of morbidity 
and mortality in older age: stroke, ischaemic heart disease, renal insufficiency and dementia.(7),(8),(9) The accelerating epidemic of hypertension in India was documented by studies done at various places across the country.(10) Hypertension being one of the leading cause of morbidity as well as mortality, especially among the elderly persons the present study was being undertaken to know the pattern of hypertension and its co-relates among the elderly patients attending the geriatric OPD.

\section{MATERIALS AND METHODS}

\section{Study Design}

Hospital-Based Cross-Sectional Study.

\section{Study Area}

Geriatric OPD, Gauhati Medical College, Guwahati.

\section{Study Period}

$1^{\text {st }}$ May, 2015 to 31st August, 2015.

\section{Study Population}

All the patients attending the Geriatric OPD of Gauhati Medical College and Hospital during the study period. Patients aged $\geq 60$ years were considered as Geriatric patients.

\section{Sampling Technique}

All the patients who attended the OPD between 10 am and 12 pm during the study period were selected purposively.

\section{Sample Size}

A total of 910 patients were selected using the above mentioned technique.

\section{Study Variables}

Age, Gender, Religion, Marital Status, Family Type, Socioeconomic Status, Literacy, Diet, Alcohol Intake, Smoking, Tobacco use, BMI were included in the study.

\section{Marital Status}

Currently married persons living with spouse were considered married. Never married, Divorced and Widower were considered as single.

\section{Socioeconomic Status}

Determined based on Modified Kuppuswamy Classification for Socioeconomic Status (SES).

\section{Diet}

Those who have never consumed fish, meat, egg or consume occasionally (<once weekly) were considered as Vegetarians. Those who consume regularly ( $\geq$ once weekly) were considered Non-Vegetarians.

\section{Alcohol Intake}

Those who have been consuming alcohol currently or had consumed alcohol regularly ( $\geq$ once a week) were considered as Alcohol Intake positive. Others were considered as negative.

\section{Smoking}

Those who currently smoke or quit smoking within 10 years were considered as smokers. Others were considered as nonsmokers.

\section{Tobacco Use (Smokeless)}

Persons using any form of smokeless tobacco for at least 1 year were considered as positive and rest as negative.

\section{Hypertension}

Hypertension was defined as per JNC 8 guidelines. Any person having Systolic BP $\geq 140 \mathrm{mmHg}$ and/or Diastolic BP $\geq 90 \mathrm{mmHg}$ were considered as Hypertensive and rest were considered as Non-Hypertensive. ${ }^{(11)}$

\section{BMI}

Body Mass Index was calculated by using Quetelet's Index. BMI of 18.5 to 24.99 were considered having normal BMI, $<18.5$ as Underweight and $\geq 25$ as Overweight.(12)

\section{Study Tools Used}

A predesigned and pretested Interview Schedule was used containing both open-ended and close-ended questions, Sphygmomanometer, Stethoscope, Bathroom Weighing Scale, Stadiometer. All the instruments were calibrated once weekly during the duration of data collection.

\section{Ethical Consideration}

The purpose of seeking information and examination was explained in detail individually to all the participants. Informed verbal consent was obtained from each participant prior to asking question and examination. Informed verbal consent was felt to be sufficient, as the study did not involve any sort of investigation/intervention. So Institutional Ethical Approval was not sought. Patient's consent was recorded by the interviewer in the schedule and duly signed.

The data collected were presented and considered in totality and was not linked to individual participant. As a part of follow-up action, individual patients were informed their BP status and intervention thereof. Measurement of Blood Pressure: BP was measured in sitting position. Two readings were taken 15 minutes apart. Averages of the two readings were considered as the Blood Pressure. Measurements were done by the Resident doctors and Interns posted in the OPD. All the resident doctors and interns were briefed about the correct BP measurement technique to maintain the consistency.

\section{Inclusion Criteria}

All the patients who attended the Geriatric Clinic with unknown BP status between 10 am and $12 \mathrm{pm}$ on the week days during the period of study were included in the study.

\section{Exclusion Criteria}

Patients already under antihypertensive medications, patients with history of being diagnosed with hypertension previously and under irregular medications, patients with history of cardiac and renal disorders, patients attending in a moribund condition, patients with history of any known psychological/psychiatric disorder were excluded from the study.

\section{Data Analysis}

Data collected were entered into MS-Excel Sheet. Data were analysed for proportion, mean, standard deviation. Significance were tested using chi-squared test, t-test wherever applicable. Risk against each of the risk factors was 
estimated calculating Odds Ratio (OR) with 95\% Confidence Interval (CI).

\section{RESULTS}

A total of 910 numbers of patients who met both inclusion and exclusion criteria were analysed, out of which $16.04 \%$ (13.7118.59) were found to be suffering from hypertension (Table\#1). The prevalence of Hypertension was found to be highest (23.5\%) among the age group of $>75$ years and lowest $(12.5 \%)$ among the age group of $60-65$ years. Among the male participants, the high BP was found to be higher (17.8\%) compared to the females, where the prevalence was found to be $12.9 \%$. High BP was found to be more among the currently married individuals (19.2\%) compared to those who are currently single (4.2\%) (Never Married, Widower, Divorced/separated).

Table\#2 reveals that among the various variables, age, religion, family type, marital status, socioeconomic status, literacy status is significantly associated $(p<0.05)$ with hypertension, whereas no significant association ( $p>0.05)$ was found between Hypertension and Gender.

Among the different risk factors studied, non-vegetarian diet [OR: 1.94 (1.25-3.01)], Alcohol Intake [OR: 2.02 (1.303.12)], Smoking [OR: 2.31 (1.61-3.33)] and Tobacco Use [OR: $1.6(1.11-2.33)]$, all were found to significantly associated with Hypertension, out of which Smoking was found to be highly significant $(p<0.0001)$ (Table\#3).

\begin{tabular}{|c|c|c|}
\hline Status & Number (N) & $\begin{array}{c}\text { Percentage } \\
\text { (95\% CI) }\end{array}$ \\
\hline Hypertensive & 146 & $16.04(13.71-18.59)$ \\
\hline Non-Hypertensive & 764 & $83.96(81.41-86.29)$ \\
\hline Total & $\mathbf{9 1 0}$ & $\mathbf{1 0 0}$ \\
\hline \multicolumn{2}{r}{ Table 1: Hypertensive Status among the Respondents } \\
\hline
\end{tabular}

\begin{tabular}{|c|c|c|c|c|c|c|c|}
\hline \multirow{2}{*}{ Variables } & \multicolumn{2}{|c|}{ HTN } & \multicolumn{2}{|c|}{ Non-HTN } & \multicolumn{2}{|c|}{ Total } & \multirow{2}{*}{$P$ value } \\
\hline & $\mathbf{N}$ & $\% 0^{* *}$ & $\mathbf{N}$ & $\%{ }^{* *}$ & $\mathbf{N}$ & $\%{ }^{* *}$ & \\
\hline \multicolumn{8}{|c|}{ Age } \\
\hline $60-65$ & 70 & $47.9 \%$ & 490 & $64.1 \%$ & 560 & $61.6 \%$ & \multirow{4}{*}{$\mathrm{P}=0.0027^{*}$} \\
\hline $66-70$ & 56 & $38.4 \%$ & 196 & $25.7 \%$ & 252 & $27.7 \%$ & \\
\hline $71-75$ & 12 & $8.2 \%$ & 52 & $6.8 \%$ & 64 & $7.0 \%$ & \\
\hline$>75$ & 8 & $5.5 \%$ & 26 & $3.4 \%$ & 34 & $3.7 \%$ & \\
\hline \multicolumn{8}{|c|}{ Gender } \\
\hline Male & 104 & $71.2 \%$ & 480 & $62.8 \%$ & 584 & $64.2 \%$ & \multirow{2}{*}{$\mathrm{P}=0.0524$} \\
\hline Female & 42 & $28.8 \%$ & 284 & $37.2 \%$ & 326 & $35.8 \%$ & \\
\hline \multicolumn{8}{|c|}{ Religion } \\
\hline Hindu & 118 & $80.8 \%$ & 548 & $71.7 \%$ & 666 & $73.2 \%$ & \multirow{4}{*}{$\mathrm{P}=0.0003^{*}$} \\
\hline Muslim & 22 & $15.1 \%$ & 210 & $27.5 \%$ & 232 & $25.5 \%$ & \\
\hline Christian & 4 & $2.7 \%$ & 4 & $0.5 \%$ & 8 & $0.9 \%$ & \\
\hline Jain & 2 & $1.4 \%$ & 2 & $0.3 \%$ & 4 & $0.4 \%$ & \\
\hline \multicolumn{8}{|c|}{ Marital Status } \\
\hline Married & 138 & $94.5 \%$ & 582 & $76.2 \%$ & 720 & $79.1 \%$ & \multirow{2}{*}{$\mathrm{P}<0.0001^{*}$} \\
\hline Single & 8 & $5.5 \%$ & 182 & $23.8 \%$ & 190 & $20.9 \%$ & \\
\hline \multicolumn{8}{|c|}{ Family Type } \\
\hline Nuclear & 122 & $83.6 \%$ & 174 & $22.8 \%$ & 296 & $32.5 \%$ & \multirow{2}{*}{$\mathrm{P}<0.0001^{*}$} \\
\hline Joint & 24 & $16.4 \%$ & 590 & $77.2 \%$ & 614 & $67.5 \%$ & \\
\hline \multicolumn{8}{|c|}{ Socio-Economic Status } \\
\hline Upper class & 34 & $23.3 \%$ & 62 & $8.1 \%$ & 96 & $10.5 \%$ & \multirow{5}{*}{$\mathrm{P}<0.0001^{*}$} \\
\hline Upper middle class & 69 & $47.3 \%$ & 332 & $43.5 \%$ & 401 & $44.1 \%$ & \\
\hline Middle class & 30 & $20.5 \%$ & 230 & $30.1 \%$ & 260 & $28.6 \%$ & \\
\hline Lower middle class & 12 & $8.2 \%$ & 119 & $15.6 \%$ & 131 & $14.4 \%$ & \\
\hline Lower class & 1 & $0.7 \%$ & 21 & $2.7 \%$ & 22 & $2.4 \%$ & \\
\hline \multicolumn{8}{|c|}{ Literacy Status } \\
\hline Illiterate & 4 & $2.7 \%$ & 158 & $20.7 \%$ & 162 & $17.8 \%$ & \multirow{5}{*}{$\mathrm{P}<0.0001^{*}$} \\
\hline Primary school & 42 & $28.8 \%$ & 376 & $49.2 \%$ & 418 & $45.9 \%$ & \\
\hline High school & 46 & $31.5 \%$ & 162 & $21.2 \%$ & 208 & $22.9 \%$ & \\
\hline Higher secondary & 30 & $20.5 \%$ & 50 & $6.5 \%$ & 80 & $8.8 \%$ & \\
\hline Graduate & 24 & $16.5 \%$ & 18 & $2.4 \%$ & 42 & $4.6 \%$ & \\
\hline
\end{tabular}

${ }^{*}$ statistically significant ** column percentage 


\begin{tabular}{|c|c|c|c|c|c|}
\hline Variables & $\begin{array}{c}\text { HTN } \\
\text { N }\end{array}$ & $\begin{array}{l}\text { Non-HTN } \\
\quad \mathbf{N}\end{array}$ & $\begin{array}{c}\text { Total } \\
\mathbf{N}\end{array}$ & $\begin{array}{c}\text { OR } \\
(95 \% \mathrm{CI})\end{array}$ & P value \\
\hline \multicolumn{6}{|c|}{ Dit } \\
\hline Non-Vegetarian & 118 & 523 & 641 & \multirow{2}{*}{$\begin{array}{c}1.94 \\
(1.25-3.01)\end{array}$} & \multirow{2}{*}{$\mathrm{P}=0.0031^{*}$} \\
\hline Vegetarian & 28 & 241 & 269 & & \\
\hline \multicolumn{6}{|c|}{ Alcohol Intake } \\
\hline Yes & 34 & 100 & 134 & 2.02 & \multirow{2}{*}{$\mathrm{p}=0.0017^{*}$} \\
\hline No & 112 & 664 & 776 & $(1.30-3.12)$ & \\
\hline \multicolumn{6}{|c|}{ Smoking } \\
\hline Yes & 92 & 324 & 416 & 2.31 & \multirow{2}{*}{$\mathrm{P}<0.0001^{*}$} \\
\hline No & 54 & 440 & 494 & $(1.61-3.33)$ & \\
\hline \multicolumn{6}{|c|}{ Tobacco Use (Smokeless) } \\
\hline Yes & 96 & 416 & 512 & 1.61 & \multirow{2}{*}{$\mathrm{p}=0.0121^{*}$} \\
\hline No & 50 & 348 & 398 & $(1.11-2.33)$ & \\
\hline \multicolumn{6}{|c|}{$\begin{array}{l}\text { Table 3: Distribution of the Respondents } \\
\text { According to the Different Risk Factors }\end{array}$} \\
\hline
\end{tabular}

*statistically significant

\begin{tabular}{|c|c|c|c|c|c|c|}
\hline \multirow{2}{*}{$\begin{array}{c}\text { Age Group } \\
\text { (In Years) }\end{array}$} & \multicolumn{2}{|c|}{ SBP } & \multirow[b]{2}{*}{ t value } & \multicolumn{2}{|c|}{ DBP } & \multirow[b]{2}{*}{ t value } \\
\hline & $\begin{array}{c}\text { HTN } \\
(\text { Mean } \pm \text { SD), N }\end{array}$ & $\begin{array}{c}\text { Non HTN } \\
(\text { Mean } \pm \text { SD), N }\end{array}$ & & $\begin{array}{c}\text { HTN } \\
(\text { Mean } \pm \text { SD), N }\end{array}$ & $\begin{array}{c}\text { Non-HTN } \\
(\text { Mean } \pm \text { SD), N }\end{array}$ & \\
\hline $60-65$ & $151.33 \pm 20.80,42$ & $\begin{array}{c}129.84 \pm 13.00 \\
286\end{array}$ & $4.604^{* * *}$ & $\begin{array}{c}92.10 \pm 5.78 \\
42\end{array}$ & $\begin{array}{c}80.5 \pm 6.62 \\
286\end{array}$ & $8.421^{* * *}$ \\
\hline $66-70$ & $\begin{array}{c}147.13 \pm 19.48 \\
46\end{array}$ & $\begin{array}{c}128 \pm 8.69 \\
126\end{array}$ & $4.547^{* * *}$ & $\begin{array}{c}90.09 \pm 6.65 \\
46\end{array}$ & $\begin{array}{c}80.97 \pm 6.75 \\
126\end{array}$ & $5.65^{* * *}$ \\
\hline $71-75$ & $\begin{array}{c}145.5 \pm 6.40 \\
8\end{array}$ & $\begin{array}{c}128.5 \pm 10.89 \\
48\end{array}$ & $4.363^{* *}$ & $\begin{array}{c}90.5 \pm 3.42 \\
8\end{array}$ & $\begin{array}{c}80.13 \pm 8.84 \\
48\end{array}$ & $4.171^{* *}$ \\
\hline$>75$ & $\begin{array}{c}145.5 \pm 5.26 \\
8\end{array}$ & $\begin{array}{c}127.5 \pm 11.65 \\
20\end{array}$ & $3.977^{* *}$ & $\begin{array}{c}87.5 \pm 3 \\
8\end{array}$ & $\begin{array}{c}79.5 \pm 7.69 \\
20\end{array}$ & $2.8^{*}$ \\
\hline & & 4: Distribution & and $D$ & th Ages (Male) & & \\
\hline
\end{tabular}

${ }^{*} \mathrm{p}<0.05,{ }^{* *} \mathrm{p}<0.01,{ }^{* * *} \mathrm{p}<0.001$

\begin{tabular}{|c|c|c|c|c|c|c|}
\hline \multirow{2}{*}{$\begin{array}{l}\text { Age Group } \\
\text { (In Years) }\end{array}$} & \multicolumn{2}{|c|}{ SBP } & \multirow[b]{2}{*}{ t value } & \multicolumn{2}{|c|}{ DBP } & \multirow[b]{2}{*}{ t value } \\
\hline & $\begin{array}{c}\text { HTN } \\
(\text { Mean } \pm \text { SD), } N\end{array}$ & $\begin{array}{c}\text { Non-HTN } \\
\text { (Mean } \pm \text { SD), N }\end{array}$ & & $\begin{array}{c}\text { HTN } \\
(\text { Mean } \pm \text { SD), N }\end{array}$ & $\begin{array}{c}\text { Non-HTN } \\
(\text { Mean } \pm \text { SD), } N\end{array}$ & \\
\hline $60-65$ & $\begin{array}{c}144.3 \pm 12.49 \\
28 \\
\end{array}$ & $\begin{array}{c}127.56 \pm 14.33 \\
204\end{array}$ & $4.615^{* * *}$ & $\begin{array}{c}93.7 \pm 6.46 \\
28 \\
\end{array}$ & $\begin{array}{c}79.92 \pm 6.28 \\
204 \\
\end{array}$ & $7.509^{* * *}$ \\
\hline $66-70$ & $\begin{array}{c}154.8 \pm 5.02 \\
10 \\
\end{array}$ & $\begin{array}{c}130.43 \pm 13.13 \\
70 \\
\end{array}$ & $7.72^{* * *}$ & $\begin{array}{c}93.6 \pm 4.34 \\
10 \\
\end{array}$ & $\begin{array}{c}81.62 \pm 8.48 \\
70 \\
\end{array}$ & $4.965^{* * *}$ \\
\hline $71-75$ & $\begin{array}{c}161 \pm 26.87 \\
4\end{array}$ & $\begin{array}{c}135.0 \pm 7.07 \\
4\end{array}$ & 1.323 & $\begin{array}{c}97 \pm 7.07 \\
4\end{array}$ & $\begin{array}{c}89.0 \pm 0.0 \\
4\end{array}$ & ----- \\
\hline$>75$ & --------------- & $\begin{array}{c}130.0 \pm 0.0 \\
6\end{array}$ & ------ & --------- & $\begin{array}{c}83.0 \pm 4.24 \\
6\end{array}$ & ---- \\
\hline
\end{tabular}

${ }^{*} \mathrm{p}<0.05,{ }^{* *} \mathrm{p}<0.01,{ }^{* * *} \mathrm{p}<0.001$

The highest mean Systolic BP among the male participants was found to be $151.33 \pm 20.80 \mathrm{mmHg}$ among the hypertensives compared to $129.84 \pm 13.00 \mathrm{mmHg}$ among the non-hypertensive in the 60-65 years' age group (Table\#4). The highest Diastolic BP was found to be $92.10 \pm 5.78 \mathrm{mmHg}$ in the hypertensives compared to $80.5 \pm 6.62 \mathrm{mmHg}$ among the non-hypertensives in the same age group (Table\#4).

Table\#4 also reveals that there is significant difference in both mean Systolic and mean Diastolic BP between the hypertensive group and non-hypertensive group, among males, across all the age groups $(\mathrm{p}<0.05)$.
The highest mean Systolic BP among the female participants was found to be $154.8 \pm 5.02 \mathrm{mmHg}$ among the hypertensives compared to $130.43 \pm 13.13 \mathrm{mmHg}$ among the non-hypertensive in the 66-70 years' age group (Table\#5). The highest Diastolic BP was found to be $97 \pm 7.07 \mathrm{mmHg}$ in the hypertensives compared to $89.0 \pm 0.0 \mathrm{mmHg}$ among the nonhypertensives in the 71-75 years' age group (Table\#5).

Table\#5 also reveals that there is significant difference in both mean Systolic and mean Diastolic BP between the hypertensive group and non-hypertensive group, among males, across all the age groups $(\mathrm{p}<0.05)$. 


\begin{tabular}{|c|c|c|c|c|c|c|c|c|}
\hline \multirow{2}{*}{ BMI } & \multicolumn{2}{|c|}{ HTN } & \multicolumn{2}{|c|}{ Non-HTN } & \multicolumn{2}{|c|}{ Total } & \multirow{2}{*}{ OR (95\% CI) } & \multirow{2}{*}{$P$ value } \\
\hline & $\mathbf{n}$ & $\%$ & $\mathbf{n}$ & $\%$ & $\mathbf{n}$ & $\%$ & & \\
\hline$<18.5$ & 12 & $11.5 \%$ & 108 & $22.5 \%$ & 120 & $20.5 \%$ & $\begin{array}{c}0.4865 \\
(0.2546-0.9297) \\
\end{array}$ & $\mathrm{P}=0.0292^{*}$ \\
\hline 18.5-24.99 & 74 & $71.2 \%$ & 324 & $67.5 \%$ & 398 & $68.2 \%$ & Ref & --- \\
\hline$\geq 25$ & 18 & $17.3 \%$ & 48 & $10 \%$ & 66 & $11.3 \%$ & $\begin{array}{c}1.6419 \\
(0.9032-2.9848)\end{array}$ & $P=0.1039$ \\
\hline
\end{tabular}

*statistically significant

\begin{tabular}{|c|c|c|c|c|c|c|c|c|}
\hline \multirow{2}{*}{ BMI } & \multicolumn{2}{|c|}{ HTN } & \multicolumn{2}{|c|}{ Non-HTN } & \multicolumn{2}{|c|}{ Total } & \multirow{2}{*}{ OR $(95 \% \mathrm{CI})$} & \multirow{2}{*}{$P$ value } \\
\hline & $\mathbf{n}$ & $\%$ & $\mathbf{n}$ & $\%$ & $\mathbf{n}$ & $\%$ & & \\
\hline$<18.5$ & 2 & $4.8 \%$ & 60 & $21.1 \%$ & 62 & $19 \%$ & $\begin{array}{c}0.2125 \\
(0.0495-0.9125)\end{array}$ & $\mathrm{P}=0.0372^{*}$ \\
\hline $18.5-24.99$ & 32 & $76.2 \%$ & 204 & $71.8 \%$ & 236 & $72.4 \%$ & Ref & --- \\
\hline$\geq 25$ & 8 & $19 \%$ & 20 & $7.1 \%$ & 28 & $8.6 \%$ & $\begin{array}{c}2.55 \\
(1.0361-6.2760)\end{array}$ & $\mathrm{P}=0.0416^{*}$ \\
\hline
\end{tabular}

*statistically significant

Among the Male participants, underweight (BMI <18.5) was found to be protective against Hypertension [OR: 0.4865 (0.2546-0.9297)] and was found to be statistically significant. Increased risk was found [OR: 1.6419 (0.9032-2.9848)] with overweight (BMI $\geq 25)$, but was not found to be statistically significant (Table\#6).

Among the Male participants, underweight (BMI <18.5) was found to be protective against Hypertension [OR: 0.2125 (0.0495-0.9125)] and was found to be statistically significant. Increased risk was found [OR: 2.55 (1.0361-6.2760)] overweight $(\mathrm{BMI} \geq 25)$, which was also found to be statistically significant (Table\#6). So, it can be inferred from the above observations that BMI is found to be inversely related to Blood Pressure.

\section{DISCUSSION}

The overall prevalence of hypertension among the study subjects $(N=910)$ was found to be $(n=146) 16.04 \%$. This was found to be less compared to the similar studies done in other setting elsewhere.(13),(14),(15),(16) These differences in the result could be attributed to the different study designs and settings adopted in the different studies. And also the fact that in the present study, already diagnosed cases of hypertension have been excluded and only the persons with unknown BP status were considered, which might have resulted in lower prevalence compared to the other studies. So in such a setting and design, even a prevalence of $16.04 \%$ has to be taken as high.

Increasing age, family type, marital status, socio-economic status and literacy rate have found to be significantly associated with high $\mathrm{BP}$, which is consistent with other studies done elsewhere.(17),(13),(16)

There is a significant association between High BP and Non-Vegetarian Diet, Alcohol Intake, Smoking and Tobacco Use. These findings are also somewhat similar to the earlier studies done.(13),(14),(17)

From Table\#4, among the male respondents it is seen that with increase in age group, the mean blood pressure systolic or diastolic decreases among both hypertensive and nonhypertensive. The difference between the means of the blood pressure among hypertensive and non-hypertensive is significant in all age groups, but the significance slightly decreases with increasing age. Highest mean SBP was found in the age group of $60-65$ years, followed by $66-70$ years' age group among those who were hypertensive. Among the hypertensive, the DBP was found to be highest in the 60-65 years' age group. This finding was also somewhat similar to the findings of the studies done by Hazarika et al(13) and Rashid AK et al.(15)

From Table\#5, among the female respondents it was found that seen that both systolic and diastolic blood pressure increases with higher age group among both hypertensive and non-hypertensive. The difference between the means of the blood pressure among hypertensive and non-hypertensive group is highly significant in the 60-65 and 66-70 years' age group. This finding was somewhat similar to the finding of Hazarika et al.(13)

From Table\#6 and Table\#7, it was found that among both males and females, lower BMI somewhat protects against high $\mathrm{BP}$ and higher BMI increases the risk to an extent. It can also be found that the risk of having hypertension significantly increases with the increase in BMI. These findings are also quite similar to studies done by Hazarika et al(13), Rashid et al(15) and Alam et al.(14)

\section{CONCLUSION}

The finding of quite a high percentage (16.04) of elderly having high BP among those with previously unknown BP status indicates that more extensive screening activity is needed, especially among the middle aged adults and elderly population, so that the hypertensives could be identified as early as possible to prevent serious complications. As high BP was found to be significantly associated with modifiable risk factors like diet, alcohol intake, smoking and tobacco usage, more extensive BCC should be carried out among the middle aged and elderly persons to avoid and modify these risk factors.

\section{LIMITATIONS}

As the study was conducted among the patients attending the Geriatric Clinic of the hospital, due to paucity of time other risk factors like physical activity, waist-hip ratio could not be assessed. Family history of hypertension was not taken into final consideration, because of the fact that most of the 
respondents were not aware of their parents' BP status. Lipid profile and blood sugar, although very relevant in this study, could not assess because of shortage of time as the entire data collection were done inside the OPD.

\section{STRENGTHS}

The study could be completed within a relatively short period, as the study setting was hospital based. Gauhati Medical College Hospital being the largest tertiary care centre in the entire North-East region with patients coming from several parts of the region, the study finding could provide us with fair idea of the Blood Pressure pattern among the geriatric population of the region. The study highlights the fact that even after the age of 60 years, there was $16.04 \%$ of the subject who were diagnosed with hypertension for the first time, which may be considered quite high.

\section{RECOMMENDATION}

Effective hypertension screening programme should be put in place to detect Hypertension among the adult population $(>30$ years), so that all the cases could be detected as early as possible and provide effective treatment. This will not only bring down the load of hypertension among the geriatric population, but also help in a long way to prevent the longterm complications of Hypertension.

\section{ACKNOWLEDGEMENT}

I would like to express my sincere thanks to Prof. Nilakshi Goswami, Department of Geriatric Medicine, GMCH, for allowing us to conduct the study in the Geriatric Clinic. I would also like to thank the Medical Officers and Resident Doctors of the Department of Geriatric Medicine for their co-operation and invaluable help during entire period of data collection. I would also like to thank the staff of Geriatric Clinic for their cooperation during the study.

\section{REFERENCES}

1. India's aging population. Population reference bureau. [Online] March 2012. [Cited: March 02, 2015.] http://www.prb.org/Publications/Reports/2012/india -older-population.aspx. (Accessed on 02/03/2015, 6.45 pm).

2. Jeyalakshmi S, Chakrabarti S, Gupta N. Situation analysis of the elderly in India. New Delhi : Ministry of Statistics and Programme Implementation, Governement of India, 2011;p 18.

3. Srinath Reddy K, Shah B, Varghese C, et al. Responding to the threat of chronic dieases in India. Lancet 2005;366(9498):1744-9.
4. Park K. Preventive medicine and geriatrics. Textbook of preventive and social medicine. Jabalpur: M/s banarsidas bhanot, 2015;23rd ed:p 594-6.

5. Yach D, Hawkes C, Gould CL, et al. The global burden of chronic diseases: overcoming impediments to prevention and control. JAMA 2004;291(21):2616-22.

6. Vokonas PS, Kennel WB, Cupples LA. Epidemiology and risk of hypertension in the elderly: the framingham heart study. J Hypertens Suppl 1988;6(1):S3-9.

7. Steyn K, Slima K, Hawken S, et al. Risk factors associated with myocardial infarction in africa the interheart study. Circulation 2005;112:3554-61.

8. Ferri CP, Schoenborn C, Kalra L, et al. Prevalence of stroke and related burden amon the older people of latin America, India and China. J Nerol Neurosurg Psychiatry 2011;82(10):1074-82.

9. Ikeda N, Saito E, Kondo N, et al. What has made the population of Japan healthy? Lancet 2011;378(9796):1094-105.

10. Gupta R. Trends in hypertension epidemiology in India. J Hum Hypertens 2004;18(2):73-8.

11. Kayce B, Twiggs J, Orlin BR. Hypertension: the slient kille: updated JNC-8 guideline recommendations. Alabama: Alabama Pharmacy Association 2015;p 4.

12. World health organization. WHO international. [Online] WHO. [Cited: May 13, 2015.] www.who.int/bmi/index.jsp?introPage=intro_3.html. (Acsessed on 13/05/2015, $10.30 \mathrm{am}$ )

13. Hazarika NC, Biswas D, Mahanta J. Hypertension in the elderly population of Assam. Journal of the Association of Physicians of India 2003;51:567-73.

14. Naushad Alam, Gopal Prasad Soni, Kamlesh Kumar Jain, et al. Prevalence and determinants of hypertension in elderly population of Raipur city, Chhattisgarh. International Journal of Research in Medical Sciences 2015;3(3):568-73.

15. Rashida AK, Azizah AM. Prevalence of hypertension among the elderly malays living in rural malayasia. Australasian Medical Journal 20011;4(6):283-90.

16. Chinnakali P, Bharathy Mohan, Ravi Prakash Upadhyay, et al. Hypertension in the elderly: prevalence and health seeking behaviour. North American Journal of Medical Sciences 2012;4(11):558-62.

17. Manimunda SP, Sugunan AP, Benegal V, et al. Association of hypertension with risk factors \& hypertension related behaviouramong the aboriginal nicoberese tribe living in car nicobar insland, India. Indian Journal of Medical Research 2011;133(3):287-93. 